\title{
Challenges Hindering the Effective Implementation of the Harmonized Modular Curriculum: The Case of Three Public Universities in Ethiopia
}

\author{
Taye Gebremariam Olamo, Yirgalem Bekele Mengistu, Yirgu Asres Dory \\ College of Social Sciences \& Humanities, Hawassa University, Hawassa, Ethiopia \\ Email: tayegmar@yahoo.com,yirgalembekele86@yahoo.com,yir-dor@yahoo.com
}

How to cite this paper: Olamo, T. G., Mengistu, Y. B. and Dory, Y. A. (2019). Challenges Hindering the Effective Implementation of the Harmonized Modular Curriculum: The Case of Three Public Universities in Ethiopia. Creative Education, 10, 1365-1382.

https://doi.org/10.4236/ce.2019.107102

Received: May 20, 2019

Accepted: July 5, 2019

Published: July 8, 2019

Copyright $\odot 2019$ by author(s) and Scientific Research Publishing Inc. This work is licensed under the Creative Commons Attribution International License (CC BY 4.0).

http://creativecommons.org/licenses/by/4.0/

\begin{abstract}
The objective of this study was to assess challenges which hinder the effective implementation of the Harmonized Modular Curriculum for Undergraduate English Language and Literature Program in Ethiopian public universities. Three universities in South Nations, Nationalities and Peoples Regional State of Ethiopia were selected as research sites. Data were gathered using questionnaire, interview, focus group discussion and observations. Instructors, students, department heads and quality assurance directors and Social Sciences and Humanities College Deans of the selected universities were respondents. The findings of the study show that the modular curriculum has not been effectively implemented due to some challenges. The challenges include that students are forced to join the Department of English Language and Literature without the basic knowledge, skills, and interest to study, which in its turn makes the teaching-learning process difficult. In addition, facilities and materials were not available at the required quantity and quality. Awareness raising training on modularization has almost been neglected, and some academic administrators and instructors were not committed to playing their roles in the implementation of the curriculum. Even some administrative bodies interfere in the grading system. Furthermore, a few courses that should be offered on a semester basis were offered in blocks, and some were illogically offered simultaneously. This implies that quality of education is given less emphasis than quantity. There was also lack of coordination and collaboration among the different parties. These all greatly hinder the effective implementation of the Nationally Harmonized English Language and Literature Curriculum.
\end{abstract}




\section{Keywords}

Modular Curriculum, Effective Implementation, Undergraduate

\section{Introduction}

Different scholars define the term "curriculum" differently. In the context of this study, it is defined as the formal and informal content and process by which learners gain knowledge and understanding, develop skills, and alter attitudes, appreciations, and values under the auspices of an academic institution (HEC, 2012 cited in Moges, 2015). According to this definition, curriculum is not only the content selected and delivered, but also the planned and unplanned activities in which individuals participate as students.

These days higher education curriculum around the world is witnessing a significant shift in its expectations to help address immediate and longer-term sustainable development challenges (Mesfin, 2016). Due to dissatisfaction with the traditional designs and in response to the changing needs of modern global society and a developing system of mass participation in higher education, modular curriculum has come into play.

The idea of modular curriculum cannot be viewed and understood dislocated from the wider and inclusive concept of curriculum (Solomon et al., 2011). Modularization is principle of dividing a curriculum into small discrete modules or units that are independent, non-sequential and short in duration where students accumulate credit for modules which can lead to a qualification for which a specified number of credit points is required. Though there are different types of modular academic programs, all share an underlying philosophy that learning can be broken down into measurable, quantifiable units of knowledge. In contrast to a traditional linear degree program comprised of a sequence of subjects, modularized degrees tend to be made up of stand-alone, independent units that can be undertaken in different orders and accumulated at different speeds. Modular degree helps students in terms of their capacity to offer flexibility, access, choice, and mobility, and also potentially allow institution to better respond to the needs of employers, expand student job markets, develop efficient uses of resources and increase chances for curricula extensiveness (Sarah, 2015).

Based on some initiatives (a rapid expansion of the Ethiopian Higher Education (HE), institutional change in teaching and learning-e.g. Change in HE delivery \& operation, establishment of quality assurance, curricular reform for undergraduate programs, promoting student-centered methods and continuous assessments, establishing academic development and resource centers, etc.), curriculum reform has been made at Ethiopian HE. In view of that, modular curriculum has come into play in the Ethiopian HE system. For example, the undergraduate curricula of different subjects have been renewed in ways that represent a modular approach for instruction and develop a range of competences for the 
graduates. Recent advancements have brought further developments in matters related to change through a compulsory adoption of a national curriculum framework and organizing course offerings in broader themes through a modular approach, and endorsement and use of continuous assessment and criteria-referenced grading (Education Strategy Center, 2012 cited in Tadesse \& Wudu, 2016: p. 4).

Considering the modular curricula, Ethiopian HE Institutions were designed to organize program modules around competence to determine the workload of students, and to consolidate the student-centered curricula (Dejen, 2016). In line with this rationale, to produce competent English language professionals, the English Language and Literature Modular Curriculum for Undergraduate Program has been harmonized and implemented in all Ethiopian public universities (Ministry of Education, 2013). Incognizant of this, the scattered courses were clustered into 14 competence-based core modules. Besides, previously neglected students' study time was given due emphasis to implement student-centered mode of learning where the instructors' main roles are designing activities, monitoring the ongoing of the learning process and facilitating learning activities. Specifically, in language modular curriculum, students are expected to work individually, collaboratively and make presentations, reports and whole class discussions, and are assessed on the basis of continuous assessment and final examination (ECERP, 2005).

Developing a curriculum is not an end by itself. This is to say that it has to be implemented so as to achieve the objectives formulated in it. What does it mean by implementing curriculum? As Morrison (2007) defines, curriculum implementation is a process of actualizing the developed curriculum into use. It is the adopting of the planned, tried and revised curriculum in learning institutions that involve interaction of students, teachers and school physical resources to produce the desired objectives. As Ornstein \& Hunkins (2004) define, curriculum implementation is a systematic process of ensuring that the developed curriculum reaches its intended consumers, and requires teamwork that starts from curriculum development down to teachers, learners, and the public at large. These definitions show that implementation of curriculum is done systematically from the lowest to the highest level of learning in each succeeding year.

Many goals of curriculum have failed to pass the planning stage due to faulty implementation. Well conceived curriculum ideas have remained virtually inert and dysfunctional. The outcome of this is the bred of graduates of higher institution who are found to be grossly deficient in practical and professional competences (Izuagba \& Atuobi, 2009). This results in the production of half baked, ill-trained and sometimes confused graduates (Idaka \& Joshua, 2005). This and other related problems should be a cause for concern to all patriotic and serious-minded stakeholder of the educational sub-sector. Against this background, this study was designed to investigate teachers' perceived causes and problems of curriculum implementation.

From the above discussions, it is possible to notice that the implementation of 
the curriculum is believed to play a crucial role in the production of competent professionals in a particular field of study. But it is not an easy task to accomplish as it demands the determination and commitment of the stakeholders, particularly the university leaders, instructors and students. It also requires adequate and quality facilities and materials. The determination and commitment of university administrators are very crucial in this regard. Instructors must assess their students continuously using different assessment methods and render the necessary support to the students. The students are also expected to take the lion's share for their own learning. For example, they should study adequately and exploit all available opportunities. It is, therefore, obvious that the implementation of the curriculum needs the willpower and commitment of all concerned bodies.

Due to different reasons, implementing curriculum successfully is not as such simple. This is to say that there are various challenges and factors which hinder the effective implementation of a curriculum, particularly pertinent to shouldering responsibilities by major stakeholders and availability of essential facilities and materials. Regarding this, researchers have identified a number of institutional factors (Administration of the institution, availability and quality of resources, learner and teacher factors) which are considered crucial to the effective implementation of a curriculum (Fullan, 2001).

Lack of resources is one of the factors which affect curriculum implementation (Jansen, 1998). To ensure that curriculum is effectively implemented, infrastructural facilities, equipment, tools and materials must be provided in adequate quantities as inadequate resources and facilities (classrooms, laboratories, libraries, etc) can affect its implementation (Ivowi, 2004). Accessibility of these facilities and resources assist in offering a wide range of reading material. Van der Nest (2012) also argues that adequate facilities are the key factors in implementing a curriculum. Van further explains that for institutions to successfully implement a curriculum there is a need for sufficient classrooms to alleviate overcrowding of learners. This is to say that the availability of resources, funds and an environment which is conducive for teaching and learning play an essential part in ensuring effective implementation of a curriculum.

Teachers play an integral part in the implementation of a curriculum as it is teachers who transform the curriculum specified as policy and implement it practically in the classrooms. Teachers' understanding, their training background, and lack of guidance and large class size are factors which make it difficult for teachers to implement curriculum (Fullan, 1991). It is obvious that teachers' commitment is important in influencing the implementation of curriculum (Jansen \& Christie, 1999). Taole (2013) also states that it is very important to provide support to teachers to achieve effective curriculum implementation. Furthermore, the gap between policy and implementation will remain open unless adequate and suitable attention is given to teachers (Dembele \& Lefoka, 2007). These all show that the role of teachers in the curriculum implementation should not be neglected. 
Another factor in the implementation of curriculum is learners as any curriculum change or innovation is planned and implemented for them. This is because their achievements are the indicators of the success or failure of a curriculum. For example, when implementing curriculum change, significance is to be given to the learners' past language learning experiences, their motivation to learn the English language, and their beliefs about the classroom norms and learning behaviors (Shamim, 1996).

The success of curriculum implementation also depends on the institution, which will use the curriculum. This is to say that leadership of an institution plays a crucial role in this respect. Good management and support to teachers are of utmost importance. The administrative support available within an institution and the communicational understanding between the teachers and the administration can create an atmosphere of motivation and productivity. On the other hand, inefficient leadership and management is one of the biggest barriers to the success of curriculum implementation (UNESCO, 2000).

In conclusion, a number of specific studies show that factors affecting curriculum implementation. For instance, Carless (1999) declares that lack of resources and insufficient curriculum time, expenses for training and lack of appropriate materials as factors that make curriculum seldom implemented as intended. In addition, contextual factors like large class sizes and resistance from administration, teachers and students also inhibit curriculum implementation (Fullan, 2007). It is therefore, timely and relevant to investigate challenges which hinder the effective implementation of the Nationally Harmonized Modular Curriculum for Undergraduate English Language and Literature Program and their potential sources.

\section{Objectives of the Study}

The general objective of this study was to assess challenges which affect the effective implementation of the Modular Curriculum for English Language and Literature Undergraduate Program. The specific objectives of the study were to:

1) Identify challenges concerning instructors', students' and academic administrators' roles and responsibilities.

2) Describe challenges regarding facilities and materials.

3) Examine challenges concerning teachers' training and awareness.

4) Describe challenges concerning assessment, course sequence and course time span.

\section{Methods and Materials}

\subsection{Research Setting}

Three public universities of Ethiopia (Hawassa, Dilla and Wolayta Sodo Universities) were selected to conduct this research for the very reason that they are relatively near to the researchers' work area and they have been implementing the English Language and Literature undergraduate modular curriculum since 
its commencement.

\subsection{Participants of the Study}

Instructors and students from the Department of English Language and Literature, and academic administrators were respondents for this study. Based on their experience, 30 instructors who taught English Language and Literature courses were selected to respond to the questionnaire and 10 of them were interviewed. Among the 30, 12, 10 and 8 of them were from Hawassa, Wolayta Sodo and Dilla Universities respectively. Again among the 30, 10 (4, 3 \& 3 from Hawassa, Wolayta Sodo \& Dilla respectively) were randomly selected for interview. On the other hand, from 180 second and third-year students, $110(40,35 \& 35$ from Hawassa, Wolayta Sodo \& Dilla) were selected respectively using random sampling technique for the questionnaire and 12 of them participated in the FGD. Three department heads and four Social Sciences and Humanities College Deans and Quality Assurance officers of the 3 universities were interviewees.

\subsection{Data Collection Instruments and Procedures}

Questionnaires, interviews, focus group discussion, classroom observation and resource centers' observations were used to gather data.

\subsubsection{Questionnaire}

Questionnaires containing both open and close-ended items were prepared for instructors and student respondents. The purpose of the questionnaires was to collect data concerning the availability and quality of facilities and materials, the commitment of major stakeholders to play the roles expected of them and the practicality of continuous assessment and the program as a whole when implementing modular curriculum.

\subsubsection{Interviews}

A semi-structured interview was used to obtain data from selected instructors, quality assurance directors. The purpose of the interviews was to get relevant information that was not obtained from the questionnaires and to supplement the responses of the questionnaires.

\subsubsection{Classroom Observation}

The researchers made six classroom observations with the aim of assessing whether both the instructors and the students are playing their roles to make the classroom teaching-learning process effective in order to implement the Harmonized English Language Modular Curriculum. A checklist was used during the observations.

\subsubsection{Resource Centers Observation}

The researchers observed the Social Sciences and Humanities College Libraries, the language laboratories and the English Language Improvement Centers (ELICs) of the 3 universities. The purpose of observation was to assess the adequacy 
and quality of facilities, materials and service provision for students as well as for instructors to effectively implement the nationally harmonized English Language and Literature for undergraduate program.

\subsubsection{Data Collection Procedures}

First, questionnaires for pilot study were distributed and improvements on the items were made. Second, the revised questionnaires were distributed and collected. Third, items that needed gathering additional information for supplementing and crosschecking the information obtained through questionnaires were identified. Forth, interviews were conducted. Then, classroom and resource centers' observations were carried out. Finally, FGD was held with students. In view of that, the data gathered were analyzed using both quantitative and qualitative methods.

\section{Results and Discussions}

\subsection{Results of Instructors' Responses}

Table 1 shows that $13(43.3 \%)$ of the respondents indicated that their dissent with statement 1 while 12 (37\%) of them assented with the statement, and (16.7\%) of them could not decide. Instructors' and department heads' interview responses, and focus group discussion results on the same issue show that most of the students did not make adequate effort to develop their skills and knowledge in English. Table 1 also shows that the majority (60\%) of the instructors dissented with statement 2. The result of instructors' interview and FGD also shows that the majority of the students did not exploit continuous assessment opportunities for their professional development. Table 1 also portrays that 27 (90\%) of the respondents did not concord with statement 3 . The results of heads' interviews and focus group discussion also signify that most of the students joined the department without sufficient basis. Finally, Table 1 also shows that 27 (90\%) of the respondents were not in accord with statement 4. Department

Table 1. Results of Instructors' questionnaire concerning students' effort \& background.

\begin{tabular}{|c|c|c|c|c|c|c|c|}
\hline \multirow{2}{*}{ No. } & \multirow{2}{*}{ Statements } & \multirow{2}{*}{ Fr. \& \% } & \multicolumn{5}{|c|}{ Responses } \\
\hline & & & SA & A & $\mathrm{U}$ & $\mathrm{D}$ & $\mathrm{SD}$ \\
\hline \multirow{2}{*}{1} & Most students in my class try to develop & Fr & 2 & 10 & 5 & 11 & 2 \\
\hline & their knowledge and skills in English. & $\%$ & 6.7 & 30.3 & 16.7 & 36.6 & 6.7 \\
\hline \multirow[t]{2}{*}{2} & $\begin{array}{l}\text { Students use continuous assessment } \\
\text { opportunities to develop their skills \& }\end{array}$ & Fr & 0 & 3 & 9 & 12 & 6 \\
\hline & knowledge in English. & $\%$ & 0 & 10 & 30 & 40 & 20 \\
\hline \multirow{2}{*}{3} & Students who have joined English Language & Fr & 0 & 0 & 3 & 15 & 12 \\
\hline & basis to be successful. & $\%$ & 0 & 0 & 10 & 50 & 40 \\
\hline \multirow{2}{*}{4} & Students join English language and Literature & Fr & 0 & 0 & 3 & 14 & 13 \\
\hline & Program on the basis of their choice. & $\%$ & 0 & 0 & 10 & 46.7 & 43.3 \\
\hline
\end{tabular}

Key: SA = Strongly Agree, $\mathrm{A}=$ Agree, $\mathrm{U}=$ Undecided, $\mathrm{D}=$ Disagree, $\mathrm{SD}=$ Strongly Disagree . 
heads' and students' responses for similar items also indicate that the majority of the students joined the department without their interest which would not be good for their success.

Table 2 shows that the majority (93.3\%) of the instructors replied that they prepare activities for the courses they teach. Students' and department heads' responses for related items also show that most of the instructors do their best for the realization of the modular curriculum. Table 2 also shows that 23 (76.7\%) of the instructors responded that they assess their students' progress continuously by using quizzes, tests, class work, homework, individual, pair and group assignments and oral presentations.. Students' and department heads' responses for related items also show that most of the instructors carry out continuous assessment properly.

Table 2 also depicts that most (83.3\%) of instructors do not get necessary facilities, materials and administrative support to implement the modular curriculum effectively. Department Heads' responses for related interview items support this. These data show that the instructors are facing these challenges in accomplishing their duties. Table 2, moreover, shows that 17 (56.7\%) of instructors reported that they did not take any training on modularization. From those (13) who took the training, only 2 of them responded that the training was adequate. Results of heads' and quality assurance directors' responses for related interview items show that awareness raising training on the modularization has almost been neglected.

Table 3 depicts that 18 (59.9\%) of instructors responded that teaching professionals in the English Language and Literature have not been given adequate emphasis. The interview responses of most instructors and heads, and quality assurance directors and college deans also indicate that teaching professionals in the area have not been given adequate emphasis. Among the participant instructors, $18(60 \%)$ of them responded that the modular curriculum has not been effectively implemented. Department heads', quality assurance directors' and college deans' 'responses for related items support this result. As indicated in Table 3, more than half (63.3\%) of the instructors did not believe that the

Table 2. Results of instructors' questionnaire concerning their responsibilities and support they need.

\begin{tabular}{|c|c|c|c|c|c|c|c|}
\hline \multirow{3}{*}{ No. } & \multirow{3}{*}{ Items } & \multicolumn{6}{|c|}{ Responses } \\
\hline & & \multicolumn{2}{|c|}{ Yes } & \multicolumn{2}{|c|}{ No } & \multicolumn{2}{|c|}{ Uncertain } \\
\hline & & Fr. & $\%$ & Fr. & $\%$ & Fr. & $\%$ \\
\hline 5 & Do you prepare activities for the course/s you teach? & 28 & 93.3 & 2 & 6.7 & 0 & 0 \\
\hline 6 & Do you assess your students' progress continuously? & 23 & 76.7 & 6 & 20 & 1 & 3.3 \\
\hline 7 & $\begin{array}{l}\text { Do you think English Language and Literature } \\
\text { instructors get the necessary facilities, materials } \\
\text { \& support? }\end{array}$ & 1 & 3.3 & 25 & 83.3 & 4 & 13.3 \\
\hline 8 & Have you taken any training on modularization? & 13 & 43.3 & 17 & 56.7 & 0 & 0 \\
\hline
\end{tabular}


Table 3. Results from instructors' questionnaire concerning emphasis given for implementing the modular curriculum.

\begin{tabular}{|c|c|c|c|c|c|c|c|}
\hline \multirow{3}{*}{ No. } & \multirow{3}{*}{ Items } & \multicolumn{6}{|c|}{ Responses } \\
\hline & & \multicolumn{2}{|c|}{ Yes } & \multicolumn{2}{|c|}{ No } & \multicolumn{2}{|c|}{ Uncertain } \\
\hline & & Fr. & $\%$ & Fr. & $\%$ & Fr. & $\%$ \\
\hline 9 & $\begin{array}{l}\text { Has teaching professionals in English Language } \\
\& \text { Literature been given adequate emphasis } \\
\text { by all concerned bodies? }\end{array}$ & 7 & 23.4 & 18 & 59.9 & 5 & 16.7 \\
\hline 10 & $\begin{array}{l}\text { Do you think that the modular curriculum } \\
\text { has been implemented effectively? }\end{array}$ & 5 & 16.7 & 18 & 60 & 7 & 23.3 \\
\hline 11 & $\begin{array}{l}\text { Do you think that the English Language \& Literature } \\
\text { Program in your university is graduating } \\
\text { competent professionals? }\end{array}$ & 0 & 0 & 19 & 63.3 & 11 & 36.7 \\
\hline
\end{tabular}

universities have been graduating English Language Professionals that satisfy the market demand. Department heads', quality assurance directors' and college deans' responses for similar item substantiated the fact that students leave the universities without equipping themselves with the essential proficiency.

\subsection{Results of Instructors' Interview}

The interviewees were first asked whether they had commitment to implement the modular curriculum effectively or not. Most of them responded that they were committed to playing their roles as they prepare materials and various activities for the courses they taught, cover course contents on time, and carry out continuous assessments. However, they did not refrain from existence of challenges that hinder them from exerting their outmost effort to effectively implement the Modular Curriculum. The second question was about the commitment of the academic administrators in implementing the curriculum. Most of the interviewees informed that the academic administrators', in particular, at college level and above, commitment is not visible. They further explained that most academic administrators only give information and directions instead of making the necessary follow up and take appropriate measures, and the instructors attributed the lack of commitment mainly due to lack of awareness and coordination.

The next question was about the students' overall capacity and motivation to work cooperatively and independently. Most of the interviewees told that the students' capacity is below the expected standard as they lack the required basic English language skills and knowledge to pursue the courses effectively, and they are ready neither to work cooperatively nor independently. As the respondents informed, the reasons for this are that first, the students who had low scores in Ethiopian Higher Education Entrance Competence Examination (EHEECE) were forced to join the department, and lack of habit to work collaboratively and misunderstanding of the essence of cooperative learning (CL). Most of CL activities are accomplished by a few active students where others get good marks 
without any effort (i.e. free-ridding \& social loafing are high). The instructors were also asked whether or not the students make adequate effort and exploit the available opportunities to develop their skills and knowledge. They responded that most of the students do not do so due to lack of required English language skills and knowledge, and not having habit of working hard.

The respondents were also asked whether the modular curriculum has been implemented effectively or not. They responded that attempts have been made to implement it effectively; however, there are different challenges like lack of adequate and up to date materials and facilities. The sixth question was about students' classroom participation. The respondents reported that the students are not active participants in the classroom due to low level of command of the language, and fear of making mistakes in front of their friends. From the classroom observations, the researchers could notice that most of the students are passive listeners. The final question was about the proficiency level of the graduates. In response to this, almost all of the instructors informed that most of the graduates leave the universities with low proficiency level as the students did not come with the basic skills and knowledge of the English language, and also most of them are not ready to improve, rather they want to score good grades without much effort. Lack of adequate reference books, internet services, laboratories, and offering block courses in incorrect sequence are also other contributing challenges.

\subsection{Result of Students' Questionnaire Responses}

Table 4 shows that $66(60 \%)$ of the respondents did not encounter problems while taking non-block courses. Results of FGD, instructors' and department heads' responses for the same issue contradict with this response as most of them responded that they encountered a problem while taking these courses. They said that they could not grasp the lessons sufficiently as some teachers rush to cover the courses' contents. The table also depicts that most (71.81\%) of them think they use continuous assessment opportunities effectively. But FGD result and the other subjects' responses reveal that the students did not use continuous assessment opportunities.

Table 4 also shows that more than half (54.5\%) of the respondents didn't have interest to join the program. Instructors' and department heads' responses also show the same result. Most (75.45\%) of them replied that their instructors carry out continuous assessment properly using appropriate methods. With regard to facilities and materials, 67 (60.9\%) of them answered that they didn't get the necessary facilities and materials. Besides, 57 (51.81\%) of them said that the English laboratories were not well equipped with adequate facilities and materials. Results from the other tools and respondents also support this. The table also shows that 49 (44.55\%) of them replied that they don't think that their universities give enough emphasis on the effective implementation of the modular curriculum. Results from the majority of other respondents support these responses. 
Table 4. Students' challenges \& efforts, \& emphasis on professional development.

\begin{tabular}{|c|c|c|c|c|c|c|c|}
\hline \multirow{3}{*}{ No } & \multirow{3}{*}{ Items } & \multicolumn{6}{|c|}{ Responses } \\
\hline & & \multicolumn{2}{|c|}{ Yes } & \multicolumn{2}{|c|}{ No } & \multicolumn{2}{|c|}{ Uncertain } \\
\hline & & Fr. & $\%$ & Fr. & $\%$ & Fr. & $\%$ \\
\hline 1 & $\begin{array}{l}\text { Have you ever encountered any problem }(\mathrm{s}) \\
\text { while taking non-block courses? }\end{array}$ & 54 & 40 & 66 & 60 & 0 & 0 \\
\hline 2 & $\begin{array}{l}\text { Have you ever encountered any problem(s) } \\
\text { while taking block courses? }\end{array}$ & 67 & 60.91 & 43 & 39.09 & 0 & 0 \\
\hline 3 & $\begin{array}{l}\text { Do you think that you have effectively used the } \\
\text { continuous assessment opportunities to be } \\
\text { competent in English? }\end{array}$ & 79 & 71.81 & 31 & 28.19 & 0 & 0 \\
\hline 4 & $\begin{array}{l}\text { Did you choose to join English Language and } \\
\text { Literature Program? }\end{array}$ & 50 & 45.45 & 60 & 54.55 & 0 & 0 \\
\hline 5 & $\begin{array}{l}\text { Do your instructors carry out continuous } \\
\text { assessment properly? }\end{array}$ & 83 & 75.45 & 27 & 24.55 & 0 & 0 \\
\hline 6 & $\begin{array}{l}\text { Do you get the necessary facilities; materials to } \\
\text { become competent professionals in English? }\end{array}$ & 40 & 36.36 & 67 & 60.90 & 3 & 2.72 \\
\hline 7 & $\begin{array}{l}\text { Do you think that the language laboratory in your } \\
\text { university is equipped with adequate and quality } \\
\text { facilities and materials to help the students practice? }\end{array}$ & 42 & 38.18 & 57 & 51.81 & 21 & 19.1 \\
\hline 8 & $\begin{array}{l}\text { Does your department/school provide the necessary } \\
\text { support to English Language and Literature students? }\end{array}$ & 48 & 43.64 & 54 & 49.09 & 8 & 7.27 \\
\hline 9 & $\begin{array}{l}\text { Does your department/school make the necessary } \\
\text { follow up for effective implementation of the } \\
\text { modular curriculum? }\end{array}$ & 41 & 37.27 & 55 & 50 & 14 & 12.73 \\
\hline 10 & $\begin{array}{l}\text { Do you think that your university gives sufficient } \\
\text { emphasis on the effective implementation of the } \\
\text { modular curriculum? }\end{array}$ & 40 & 36.36 & 49 & 44.55 & 21 & 19.09 \\
\hline
\end{tabular}

\subsection{Results of Students' Focus Group Discussion (FGD)}

From the FGD, the researchers could understand that the students did not get any training on modularization which largely prevents them from playing their role in the implementation of the curriculum. The students also responded that they did not use their home study time properly rather they only study during tests and exams sticking only at reading handouts given by instructors. They admitted that most of the time they focus on getting good grades instead of developing skills and knowledge, and did not properly do continuous assessments activities. They added that they lack focus to do different activities in groups, pairs or individually rather are dependent on their teachers and group leaders to complete assignments.

The discussants revealed that most of their classmates hardly participated in the class because of problems in their command of the language and fear of peer criticism. Instructors' responses and our classroom observation result confirm this. Almost all the participants reflected that many of them joined the department without the necessary skills and knowledge and interest. 


\subsection{Results of Department Heads' Interview}

The first question to the heads was about students' efforts. Two of them replied that most of the students do not endeavor adequately. But one of them reported they try though their background related problems affect them to do so. Two of them said that the students joined the department without basic skills, knowledge and interest which prevents them from making their best.

Second, the researchers questioned the interviewees whether the instructors in the program are committed or not to shoulder responsibilities. All of them said that the instructors try to do their best yet they face various challenges and there are few instructors who did not shoulder their responsibilities mainly due to lack of awareness. According to the informants, though the instructors carry out continuous assessment appropriately, deliver lessons properly, prepare suitable and various activities and render their help for students, still they face challenges related to lack of materials and facilities, students' capacity and interest, time and sequence of courses, lack of awareness on the implementation of the curriculum.

Another question was about the commitment of academic administrators in shouldering their responsibilities in the implementation of the modular curriculum. The interviewees informed that the academic administrators' commitment in that regard is very low and invisible as they simply give information and instructions. As the interviewees explained, the academic administrators' inadequate commitment emanates from lack of awareness on the essence and implementation of the modular curriculum.

Next, the heads were asked what the proficiency level of graduates would like in view of the current teaching-learning standard. Hence, they stated that the graduates' proficiency level would be below the required standard as they attributed to lack of the required proficiency in the graduates to decline in the quality of English Language education starting from the lower level and lack of commitment in the stakeholders to put the curriculum into practice. The final question was concerned with the availability and accessibility of adequate and quality materials and facilities. They explained that the necessary facilities and materials were not available and accessible at the required standard. They said that the language laboratories are not functioning properly because of some problems, there are no up-to-date course materials and the internet service is very poor and rarely accessible, particularly for students.

\subsection{Results of Quality Assurance Officers and College Deans' Interview}

The officers were first asked about their commitment. They responded that they are committed for the implementation of the curriculum by following, checking, and assessing whether it is implemented as it is intended or not. They said that they use standardized guidelines and follow up its implementation through the quality coordinators in the colleges, contact the departments and check if things are going on as planned, and give supports to the department heads, students 
and the English Language Improvement Centre (ELIC) by facilitating trainings. But instructors' and heads' responses for similar issue reveal that the officers are not doing well. The officers in their side admitted that they often receive grievances from instructors and students in connection with block courses.

With regard to the commitment of the concerned bodies for the implementation of curriculum, the interviewees said that the concerned bodies are committed as all of the problems can be connected to the management bodies in Ministry of Education who are not responding adequately. On the other hand, with regard to giving training on the modular curriculum, the officers admitted that there was lack of awareness raising trainings.

Regarding the graduates' proficiency, the interviewees said that though there were few best students, most of them are not proficient as they had been facing various challenges. They also explained that admitting students with skills and knowledge gaps to universities are problematic as this will be difficult to bring change at university level and to produce proficient graduates. The participants also mentioned that students' placement is as one of the challenges for the production of proficient graduates.

\subsection{Results of Resource Centers and Classroom Observations}

From the observations of the three universities, Social Sciences and Humanities Libraries, the researchers learned that the libraries are not satisfying the users' demands for the reference books available are inadequate and out of date, and the libraries are hardly providing e-book services, due to lack of human power, rooms and internet services. As the researchers observed, the language laboratories of the 3 universities are somewhat furnished with the necessary equipment and facilities; however, they were not fully functioning.

During the observations, the researchers were also able to notice that 2 of the 3 ELICs serve their purpose effectively as they offer different trainings for students and instructors, organize students in different language clubs and help them develop their command of the language. They also lend students and instructors various reading, and audio-video materials; however, the students are not benefiting from the services provided. One of the three ELICs; however, was not providing visibly serve for the users as it had no office and reading and audio-video materials to run its activities properly.

According to the results of resource centers and classroom observations, students get internet services mainly at centers set for that purpose, and in libraries and around buildings where internet service is available. So, the students are hardly benefiting from the internet service to develop their skills and knowledge. Instructors are relatively in a better condition with regard to access for internet service.

From classroom observations, the researchers were able to notice that most of the instructors were doing well in running the teaching/learning process effectively. This because most of them were found conducting the daily lessons effectively, preparing themselves to monitor, facilitating and supporting students' 
learning. However, most of the instructors had a limitation with regard to re-organizing students for pair or group work activities, reinforcing peer learning and using peer or group correction for giving feedback. Regarding students, only a limited number of them were found participating in pairs and groups actively, and not actively working either individually.

\subsection{Discussions}

Though students are expected to work hard and required to play a key role to become competent professionals, according to the findings of this study, unfortunately most of them are not in that status. This is to mean that as the respondent instructors informed, sadly most of the students were found not using continuous assessment opportunities as intended though it is suggested that they should use these opportunities to get feedback to develop their skills and get knowledge.

Based on the data, it is possible to say that the selection of students for English Language and Literature Program has not been properly accomplished. The evidence for this is that the respondent instructors pointed out those students' inadequate knowledge, skills and motivation, lack of the habits of referring books as challenges which are hindering the effective implementation of the curriculum. The instructors also mentioned that they were not satisfied with the supply of facilities, materials and support which help them implement the modular curriculum. These all show that the students encounter problems related to time, facilities and their potential while taking both block and non-block courses.

Based on the finding, the researchers were able to understand that one of the decisive elements in the implementation of modular curriculum is the little commitment of stakeholders. Inadequate commitment by concerned stakeholders, lack of awareness raising trainings and coordination among the responsible bodies, and offering 2 or 3 block courses at once as some of the challenges hindering the effective implementation of the curriculum. For example, the academic administrators do not give adequate and immediate responses for requests and comments related to facilities, materials, courses, etc. rather than simply suggesting shortening the contents until the curriculum is revised and informing the concerned bodies about the need to revise it. They do not even make adequate efforts to support instructors and students with regard to effective implementation of modular curriculum. Furthermore, they do not give due emphasis on the evaluation and revision of the curriculum and hardly prepare awareness raising trainings. Hence, it is possible to say that the effective implementation of the modular curriculum is questionable; which indicates that the universities are not graduating competent professionals in English.

As the key informants explained, students with low academic and English language background join the department without their interest which negatively affects their commitment and success. Based on the results, we can say that most students are not shouldering their responsibilities to make the classroom 
teaching/learning process effective. Moreover, it was found that most of them do not use their time properly and exploit the available opportunities rather depend on few clever students. According to the department head's interview results, it is also possible to say that ambitious attrition rate plan of some universities leads most of the students to be reckless as they know that they will get at least " $\mathrm{C}$ " without making any visible effort.

\section{Conclusion}

The aim of this research was to investigate challenges which hinder the effective implementation of the Undergraduate English Language and Literature Program Curriculum. To that end, different data gathering methods were employed and concerned stakeholders were involved as respondents. Based on the findings of the study, the following conclusions are made.

Students who join the Undergraduate English Language and Literature Program lack the basic skills and knowledge of the language to study it and to be successful as they are low academic achievers in National Exam and forced to join the department without their interest.

> Most of the instructors are committed to playing their role in the effective implementation of the modular curriculum by delivering the courses using the recommended mode of learning, assessing students' progress properly and rendering their help to the students so as to produce competent professionals. However, there are some who do not do so due to lack of awareness on the modularization and lack of care for the production of competent professionals.

> Some academic administrators are not committed to playing their role in the implementation of the modular curriculum. For instance, they do not give due emphasis and make the required follow up and render support for the concerned parties to produce competent professional in the area due to lack of awareness on the essence and implementation of modularization.

$>$ There are several problems in connection with adequacy and quality of facilities and materials like up-to-date references in the colleges' libraries, e-book service, internet access for students, and offices with facilities for teachers in the universities. The language laboratories and the English Language Improvement Centers are not fully functioning due to some problems.

> There are challenges regarding courses in the curriculum as time given for block courses is very short to have sufficient practice, assessment and in-depth understanding of the courses' contents and as some are illogically sequenced and some are offered at the same time.

> Some management bodies interfere in the grading system when students score low grades and force instructors to improve the grades which greatly diminishes the motivation of both the instructors and the students to work hard.

Raising the awareness of the stakeholders (students, instructors and academic administrators) on the effective implementation of the modular curriculum 
in the study setting has been neglected.

$>$ There is no collaborative working among the different stakeholders, starting from departments up to top academic administrators which greatly harms the effective implementation of the curriculum and production of proficient professionals.

The Modular Curriculum for Undergraduate English Language and Literature Program is not effectively implemented due less commitment and participation of the stakeholders(students, instructors and academic administrators), and lack of adequate and quality materials and facilities.

\section{Recommendations}

Based on the above conclusions, the following recommendations are forwarded.

- Awareness raising trainings on how to implement modular curriculum should be given for students, instructors and academic administrators timely and exhaustively.

- Academic administrators should make the required follow up, provide the essential support and take corrective measures in order to implement the modular curriculum effectively.

- Students who have the basic skills and knowledge of the English language and the interest to study it should be selected to join the English Language and Literature Department.

- In the universities, the necessary materials, resources and facilities, internet services, etc. should be made available to create conducive conditions for students. Besides, the libraries, the language laboratories and the English Language Improvement Centers should be equipped with adequate and up-to-date materials and facilities.

- The modular curriculum should be reviewed and problems related to offering courses in blocks, sequencing courses and contents of courses should be solved.

- All concerned parties should give great emphasis on quality of education instead of the reduction of attrition rate and unnecessary interference in the grading system.

- All concerned bodies should work in coordination and collaboration to implement the modular curriculum effectively.

- Other similar studies should be conducted in other universities in order to strengthen the findings of this research.

\section{Conflicts of Interest}

The authors declare no conflicts of interest regarding the publication of this paper.

\section{References}

Carless, D. R. (1999). Large-Scale Curriculum Change in Hong-Kong. In C. Kennedy, P. 
Doyle, \& C. Goh (Eds). Exploring Change in English Language Teaching (pp. 19-29). Oxford: Macmillan Heinemann.

Dejen Chaka (2016). Practices of EFL Modular Instruction: The Case of Undergraduate Program of English Language and Literature. Ph.D. Thesis, Addis Ababa: Addis Ababa University.

Dembélé, M., \& Lefoka, P. (2007). Pedagogical Renewal for Quality Universal Primary Education: Overview of Trends in Sub-Saharan Africa. International Review of Education, 53, 531-553. https://doi.org/10.1007/s11159-007-9066-8

Eastern Caribbean Education Reform Project (ECERP) (2005). Curriculum Harmonization.

Fullan, M. (1991). The New Meaning of Educational Change. London: Cassell.

Fullan, M. (2001). The New Meaning of Educational Change (3rd ed.). London: Teachers College Press.

Fullan, M. (2007). The Meaning of Educational Change. New York: Routledge.

Idaka, I. I., \& Joshua, M. T. (2005).Assessment of the Preparedness of Nigerian Academics for Evaluation by Students. Education for Today, 5, 17-28.

Ivowi, U. M. O. (2004). Curriculum Implementation: Implication for School Administration. In A. O. K. Noah, D. O. Shonibare, A. A. Ojo, \& T. Olujuwon (Eds.). Curriculum Implementation and Professionalizing Teaching in Nigeria. Lagos: Untral Educational Services.

Izuagba, A. C., \& Atuobi, A. O. (2009). Quality Education through Innovation: Examples of Tertiary Institution in Nigeria. European Journal of Social Sciences, 10, 605-613.

Jansen, J. \& Christie, P. (1999). Changing Curriculum: Studies on Outcomes-Based Education in South Africa. Kenwyn: Juta \& Co.

Jansen, J. (1998). Curriculum Reform in South Africa: A Critical Analysis of Outcomes-Based Education. Cambridge Journal of Education, 28, 321-331. https://doi.org/10.1080/0305764980280305

Mesfin, S. (2016). The Curriculum Development Process of the New Engineering Education Program and Its Practices in Ethiopia: The Case of Three Higher Engineering Education Institutions. Unpublished Ph.D. Thesis, Addis Ababa: Addis Ababa University.

Ministry of Education (2013). Nationally Harmonized Modular Curriculum for Undergraduate English Language and Literature. Addis Ababa.

Moges, L. (2015). Modularization and the Practices of Module Development in Selected Ethiopian Universities. Unpublished Ph.D. Dissertation, Addis Ababa: Addis Ababa University.

Morrison, G. S. (2007). Early Childhood Education Today. Pearson Merill, NJ: Prentice Hall.

Ornstein, A.C., \& Hunkins, F. P. (2004). Curriculum: Foundations, Principles, and Issues. Toronto: Pearson.

Sarah, F. (2015). The Benefits and Challenges of Modular Higher Education Curricula. Issues and Ideas Paper. Melbourne Centre for the Study of Higher Education.

Shamim, F. (1996). Learner Resistance to Innovation in Classroom Methodology. In H. Coleman (Ed.), Society and the Language Classroom (pp. 105-121). Cambridge: Cambridge University.

Solomon, A. et al. (2011). Academic Staff's Views and Practices of Modular Course Delivery: Graduate Program at Addis Ababa University in Focus. The Ethiopian Journal of Education, vol. XXXI, No. 2, 63-106. 
Tadesse, T., \& Wudu, M. (2016). The Prevailing Practices and Challenges of Curriculum Reform in Ethiopian Higher Education: Views and Responses from Within. Australian Journal of Teacher Education, 41, 87-106.

https://doi.org/10.14221/ajte.2016v41n10.6

Taole, M. J. (2013). Teachers' Conceptions of the Curriculum Review Process. International Journal of Educational Sciences, 5, 39-46. https://doi.org/10.1080/09751122.2013.11890059

UNESCO (2000). Education for All: Meeting Our Collection Commitments. Paris: UNESCO.

Van der Nest, A. (2012). Teacher Mentorship as Professional Development: Experiences of Mpumalanga Primary School Natural Science Teachers as Mentees. Thesis, Gauteng: University of South Africa. 